\title{
Contribuciones del CAPITAL SOCIAL \\ EN LA CONFORMACIÓN DE SISTEMAS REGIONALES \\ DE INNOVACIÓN PARA EL DESARROLlO
}

\author{
Héctor Eduardo Cardona Carmona ${ }^{1}$
}

\section{Resumen}

En el presente artículo se analiza la influencia que tienen los valores inherentes al capital social en la consolidación de sistemas regionales de innovación, para el desarrollo de las sociedades. En el desarrollo del tema se hace alusión a aspectos relacionados con el concepto de capital social, entendido como herramienta teórica útil para comprender las dinámicas propias de los sistemas regionales de innovación, así como la descripción de las características de un sistema de innovación y los elementos en común que estas tienen con valores como la confianza, la cooperación, la solidaridad y la reciprocidad.

\section{Patalubras ollave}

Capital Social, Sistemas Regionales de Innovación, Conocimiento, Desarrollo, Interacciones, Valores, Pobreza, Cooperación.

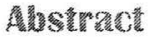

The influence of values inherent to the social capital has in the regional innovation systems consolidation for the society's development, will be analyzed in this article. Along this topic,

1 Sociólogo, Magíster en Educación y Desarrollo Humano, candidato a doctor en Estudios sobre Ciencia y Tecnología, y Gestión de la Innovación Tecnológica. Asesor de Líneas de Investigación Instituto Tecnológico Metropolitano, Medellín. hectorcardona@itm.edu.co 
there's a reference of aspects related to the social capital concept, as an useful theoretical tool used in order to understand their own dynamical regional innovation systems, as well as the characteristics description of an innovation system and the common elements this have with values like: Confidence, cooperation, solidarity and reciprocity.

\section{Key words}

Social capital, Regional Innovation Systems, Knowledge, Development, Interactions, Values, Poverty, Cooperation. 


\section{1.}

El presente artículo tiene como objetivo analizar la incidencia del capital social en la conformación de sistemas regionales de innovación, en el contexto de sociedades menos desarrolladas, como es el caso de América Latina. Para ello, partiré de la siguiente hipótesis: las sociedades menos desarrolladas cuentan en la actualidad con sistemas regionales de innovación débiles, como consecuencia de la conformación de bajos niveles de capital social que obstaculizan el desarrollo.

América Latina es una región que en la actualidad atraviesa por un cúmulo de problemáticas de carácter social, económico y cultural, que se traducen en niveles de pobreza ${ }^{2}$ crecientes para buena parte de la población, dificultándose así el acceso al desarrollo humano y social. Entre las causas de los problemas se encuentran los bajos niveles de educación y participación ${ }^{3}$, la corrupción, la falta de inversión en ciencia y tecnología, entre otros.

2 Pobreza es un término cuyo significado está fuertemente investido por la cultura: no sólo ha adquirido distintos sentidos en distintos contextos históricos sino que hoy mismo para distintas instituciones, comunidades y personas tiene connotaciones diferentes. Amartya Sen es uno de los pensadores que ha hecho aportes más relevantes en este sentido. Este autor destaca que el desarrollo debe ser visto como un proceso que expande la libertad que experimenta la gente. El desarrollo requiere la superación de los factores principales que impiden la libertad: tanto la pobreza como la tiranía, la falta de oportunidades económicas como la privación social sistemática, la negligencia en los servicios públicos como la intolerancia de estados represivos. A pesar de un crecimiento sin precedentes en la opulencia, el mundo contemporáneo niega las libertades básicas a un vasto número de personas. Muchas veces la falta de las libertades fundamentales se relaciona directamente con la pobreza económica, que roba a la gente la libertad para satisfacer su hambre, para obtener nutrición suficiente, para obtener remedios para enfermedades curables, o la oportunidad de estar bien vestidos o cobijados, o disfrutar de agua limpia o servicios sanitarios. Desde esta perspectiva ya no es el crecimiento económico el que asegura la superación de la pobreza sino todo aquello que permita generar ámbitos donde las personas tengan libertad para desarrollar sus propias capacidades.

3 Según los resultados arrojados por el latinbarómetro aplicado en los diferentes países que conforman la región latinoamericana durante los últimos años, se evidencia un marcado nivel de inconformidad por el funcionamiento de la democracia, los encuestados manifiestan la necesidad de una democracia más al servicio de la población, lo que se traduce en la demanda de mayores niveles de participación. 
Entre los diversos estudios que se han realizado en los últimos años, para diagnosticar la situación socioeconómica en que se encuentran las sociedades latinoamericanas, cobra especial interés los trabajos dedicados a analizar aquellas forma organizativas y de interacción social que caracterizan a los países, las regiones y las localidades; entre los cuales se cuenta con aquellas investigaciones y estudios dedicados a explicar, analizar y comprender cómo se da la construcción de capital social y cómo esto afecta el desarrollo.

En este sentido, son notorios los esfuerzos que tanto el mundo académico como algunas organizaciones e instituciones dedicadas al conocimiento y desarrollo de la realidad latinoamericana vienen realizando, para tratar de realizar aportaciones que contribuyan a la solución de los agobiantes problemas que aquejan a la mayoría de las personas que conforman nuestras sociedades. Entre otras, podemos mencionar: el BID, la CEPAL, la Universidad del Estado de Michigan, el Centro de Estudios Latinoamericanos y del Caribe, el Centro de Estudios Avanzados para el Desarrollo Internacional, el PNUD.

Algunas preguntas que interesa responder en las siguientes líneas son: ¿cómo se ha dado históricamente, los procesos de conformación de capital social en América Latina?, ¿cuál es el diagnóstico sobre la existencia de capital social actualmente, en América Latina?, ¿cómo ha incidido la configuración de capital social en el desarrollo de América Latina?, ¿cuál es la situación de los sistemas regionales de innovación latinoamericanos?, ¿cuál es la correlación entre capital social y sistemas regionales de innovación en América Latina?

En cierta medida, los países desarrollados no tienen los problemas de participación, confianza, cooperación, asociatividad, conciencia cívica y valores éticos con los cuales cuentan sociedades menos desarrolladas, como es el caso de los países de América Latina. Para nadie es un secreto que las sociedades latinoamericanas presentan muchos vacíos en el funcionamiento de sus organizaciones e instituciones, situación que dificulta lograr avances en materia de desarrollo, por esta razón se hace apremiante analizar 
cuales pueden ser los mecanismos y estrategias que contribuyan a contrarrestar estas limitaciones y así poder avanzar en el logro del mejoramiento del desarrollo y la calidad de vida de la gente.

Es también un hecho reconocido que los sistemas de innovación en los países menos desarrollados, se caracterizan por presentar grandes debilidades, y que apenas en los últimos años empiezan a ser motivo de preocupación, por parte de los analistas dedicados al tema y de aquellas personas responsables de crear políticas públicas para la innovación y el desarrollo. En este sentido, vale la pena analizar las posibles implicaciones, que tienen aquellos valores constitutivos del capital social en el funcionamiento de los sistemas regionales de innovación orientados hacia el desarrollo.

Para el tratamiento del tema, se realizará inicialmente un análisis acerca del concepto de capital social, desde la perspectiva de sus antecedentes, enfoques y críticas. También se dedicará un apartado a discutir algunas de las posibles relaciones existentes entre el capital social y el desarrollo. Al final se plantearán algunas ideas concernientes a la incidencia del capital social en los sistemas regionales de innovación y algunas conclusiones que articulen los aspectos tratados en las líneas siguientes.

\section{EL CONCEPTO DE CAPITAL SOCIAL: ANTECEDENTES, ENFOQUES v cointucas}

En el presente apartado se analizará en un primer momento en qué consiste el capital social, sus antecedentes, sus principales corrientes, sus enfoques y autores y algunas críticas que se le han hecho a este concepto o teoría. Al finalizar se realizará unas consideraciones de carácter epistemológico, acerca de si puede concebirse el capital social como una teoría o como un paradigma, tal como lo sugieren algunos autores.

Las ideas que configuran el concepto de capital social, no pueden ser consideradas inéditas en el ámbito de las ciencias sociales. Aquellas nociones básicas que incorpora la noción de capital social pueden identificarse, a modo de influencias y antecedentes, en 
disciplinas como la antropología, la filosofía, la ética, las ciencias políticas y en trabajos clásicos de la sociología ${ }^{4}$.

Ejemplos de lo anterior, pueden identificarse en el concepto de cohesión social que en su momento fue introducido por Durkheim como defensa del individuo ante su autodestrucción, o en la alusión de Marx al proceso de transformación de la "clase en sí" en "clase para sí", noción equiparable a lo que algunos teóricos actuales denominan "empoderamiento". También es posible asociar a algunas de las nociones de capital social, la idea sociológica de consenso, entendida como el acuerdo de los miembros de un grupo, comunidad o sociedad sobre los valores básicos de convivencia ${ }^{5}$. Igualmente, podemos identificar en los planteamientos que se hacen desde el capital social, alusiones recurrentes a la noción de cultura, que ha sido empleada con profusión tanto en sociología como en antropología; entendida como aquellos valores, normas y bienes materiales e inmateriales, característicos de un determinado grupo. Y ni qué decir del concepto de sociedad, el cual constituye uno de los más importantes en sociología, para hacer alusión a un grupo de personas que vive en un territorio determinado, que está sometido a un sistema común de autoridad política, y que es consciente de poseer una identidad que lo distingue de los otros grupos que lo rodean. Finalmente (para citar un último ejemplo de lo que sería una lista larga ${ }^{6}$ ), encontramos el concepto de poder asumido como la

4 La preocupación por las fuentes de la solidaridad social pueden rastrearse hasta los mismos orígenes de las ciencias sociales. Ya a fines del siglo XIX, Emile Durkheim señalaba la importancia de las relaciones sociales en la cooperación social, como fuente fundamental de solidaridad social en las sociedades modernas. Un cuerpo social "saludable" era aquel en el que los individuos mantenían múltiples y variadas relaciones entre sí y compartían simultáneamente valores y sentimientos comunes hacia la sociedad como un todo.

5 Algunos teóricos de la sociología han subrayado con fuerza la importancia del consenso como base de la estabilidad social. Estos autores creen que toda sociedad destinada a durar un período sustancial de tiempo supone un sistema axiológico común de creencias compartidas que mantiene la mayoría de la población.

6 Es innegable la influencia que en el tema del capital social, también tienen conceptos sociológicos como: cambio social, organización, acción colectiva, clase, conflicto, estructura social, evolucionismo social, grupo, institución, movimiento social, relaciones formales e informales, socialización, rol social, normas y valores. 
capacidad de los individuos, o los miembros de un grupo, de lograr los objetivos o fomentar los intereses que mantienen.

El término capital social aparece en la década de los noventa de manera prolífica, en diferentes trabajos provenientes de las disciplinas sociales. Para algunos autores el capital social se constituye en un paradigma, para otros es una teoría y en algunos casos es considerado, simplemente, como una modalidad de prácticas sociales propia de cualquier grupo humano ${ }^{7}$.

El concepto capital social como cualquier otro concepto, cuenta con defensores y detractores. Para citar un ejemplo de las visiones antagónicas que se puede identificar en la literatura revisada frente al capital social, quisiera traer a colación dos concepciones contrarias, provenientes de dos autores importantes en el contexto de las problemáticas del desarrollo en América Latina, una es la de Alejandro Portes y la otra de Sergio Boisier.

Para Portes (2004), la teoría del capital social es una teoría de alcance intermedio, que se constituye en herramienta teórica de gran valía, a la hora de investigar la realidad social de América Latina. Según este autor, frente al fracaso de las grandes teorías sociológicas (como el marxismo y el estructural funcionalismo), para dar explicación a los problemas sociales contemporáneos de América Latina, surge como alternativa explicativa la teoría del capital social. Por el contrario, para Boisier (2003) el capital social es considerado,

una moda desarrollista, que no se hubiera impuesto, probablemente, si desde el seno de una de las instituciones pilares del neo-liberalismo (el Banco Mundial) no se hubiese dado la 'orden' de validar la confianza interpersonal o capital social, como el puente imprescindible para viabilizar el trickling down o derrame o chorreo desde el plano macro al plano microsocial, en donde circulan los 'bípedos implumes', en la magnífica expresión de don Miguel de Unamuno para referirse a las personas, legitimando un modelo de política económica sujeto a una creciente repulsa mundial [Boisier, 2003: 64].

${ }_{7} \quad$ Volveremos sobre este punto al final del presente apartado. 
Pese a estas posturas antagónicas, que es frecuente encontrar en la literatura referida al capital social ${ }^{8}$ e independientemente de que se esté de acuerdo con una $u$ otra ${ }^{9}$, no se puede desconocer el auge de este concepto en el ámbito de las ciencias sociales y su importancia (tal como la concibe Portes), para la explicación y resolución de problemas que tienen lugar en buena parte de las sociedades actuales, menos desarrolladas. A continuación se mostrará qué se entiende por capital social, teniendo como base algunas definiciones aportadas tanto por teóricos como por algunos organismos internacionales, que se han ocupado del tema.

En autores como Bourdieu (1986), el término de capital no se reduce al capital económico. El concepto de capital se extiende a toda energía susceptible de producir efectos sociales y de ser utilizada (conscientemente o no) como instrumento en la concurrencia social. El conjunto de capitales constituye los espacios sociales, los cuales están constituidos por los agentes que ocupan plazas jerarquizadas y que persiguen diferentes bienes escasos (capitales y legitimación) y por los conflictos que son inherentes a los diferentes campos ${ }^{10} \mathrm{de}$ actividad que se desarrollan a partir de las posiciones y según las propiedades y modalidades de percepción y de acción según habitus $^{11}$ diferenciados. Bourdieu (1986) habla de capital económico, capital cultural, capital simbólico y capital social. Define el capital social como el conjunto de relaciones sociales, es decir, como la

8 En las memorias de la conferencia internacional "Hacia un nuevo paradigma: Capital Social y reducción de la pobreza en América Latina y el Caribe", organizada por la CEPAL y la Universidad del Estado de Michigan (2001) puede apreciarse con claridad este debate.

$9 \quad$ Más adelante se hará una toma de postura al respecto.

10 El concepto de campo es para Bourdieu (1986), la red de relaciones entre las posiciones objetivas que hay en él. Estas relaciones existen separadas de la conciencia y de la voluntad colectiva. No son interacciones ni lazos intersubjetivos entre los individuos. Los ocupantes de las posiciones pueden ser agentes o instituciones, y están constreñidos por la estructura del campo.

11 El habitus incluye las estructuras mentales o cognitivas mediante las cuales las personas manejan el mundo social. Las personas están dotadas de una serie de esquemas internalizados por medio de los que perciben, comprenden, aprecian y evalúan el mundo social. 
suma de recursos actuales (reales) o virtuales (potenciales) de un individuo o grupo por el hecho de la posesión de una red durable de relaciones, de conocimientos y reconocimientos mutuos más o menos institucionalizados.

A comienzos de la última década del siglo veinte, con base en los hallazgos de Bourdieu, dos investigadores sociales, James Coleman y Robert Putnam, abordaron el tema del papel que desempeña dicho capital como activo fundamental en la dinámica de las sociedades, desde ángulos distintos.

Putnam (1995) señala que el capital social comporta elementos de convivencia que una comunidad ha apropiado y que posibilitan la coordinación entre partes involucradas y la respectiva cooperación, con miras a un beneficio común. Esto supone que el trabajo dentro de comunidades en donde se comparten confianza, responsabilidad mutua, acciones colectivas, empoderamiento, valores y redes, entre otros aspectos, ha de ser más efectivo si se le compara con el trabajo en comunidades no cohesionadas, desde ningún punto de vista. En este sentido, el capital social es el activo que hace que el comportamiento operativamente eficaz de la sociedad y de sus diferentes formas de organización -económica, política, social, cívica-redunde en beneficio general. Para optimizar esta ecuación, son definitivos factores como valores, normas, reglas, redes y nociones afines. Putnam, considera que el capital social está conformado fundamentalmente por el grado de confianza existente entre los actores sociales de una sociedad, las normas de comportamiento cívico practicadas y el nivel de asociatividad. Para él, estos elementos muestran la riqueza y fortaleza del tejido social.

Para James Coleman (1990) el capital social constituye un recurso cuya particularidad radica en ser algo inherente a la estructura de las relaciones sociales. Este recurso facilita el logro de objetivos personales que no podrían alcanzarse en su ausencia o conllevarían un costo mucho más alto. Para el autor, el capital social consiste en "una diversidad de entidades con dos elementos en común: todos consisten en algún aspecto de la estructura social 
y facilitan ciertas acciones de los actores dentro de la estructura” (Coleman, 1990: 302).

Por otro lado, en la Universidad de Michigan (1994), un equipo interdisciplinario de economistas, sociólogos, cientistas políticos y antropólogos que ha conformado el "Grupo de Interés del Capital Social", lo define como los beneficios potenciales, ventajas y tratamiento preferencial que resulta de la simpatía y sentido de obligación de una persona o grupo hacia otra persona o grupo de personas. El Capital Social también incluye los potenciales beneficios, ventajas y tratamiento preferencial que se origina en la simpatía y sentido de obligación hacia el yo idealizado.

Desde la perspectiva de la CEPAL, el capital social se entiende como el conjunto de relaciones sociales basadas en la confianza y los comportamientos de cooperación y reciprocidad. Por su parte el BID ha puesto un mayor acento en las dimensiones éticas y culturales del capital social, teniendo en cuenta factores como el clima de confianza social, grados de asociatividad, conciencia cívica, valores éticos y la cultura entendida como "manera de vivir juntos". El PNUD ha desarrollado un tipo de conceptualización y medición de capital social entendido como relaciones informales de confianza y cooperación, asociatividad formal en organizaciones de diverso tipo, y marco institucional normativo y valórico de una sociedad que fomenta o inhibe las relaciones de confianza y compromiso cívico. Por asociatividad se entiende la organización voluntaria y no remunerada de individuos o grupos que establecen un vínculo explícito, con el fin de conseguir un objetivo común.

Como puede verse, el concepto de capital social al igual que cualquier concepto desarrollado por las ciencias sociales, no está exento de connotaciones y posturas ideológicas que van desde las más progresistas (preocupadas por el empoderamiento, la ciudadanía, el pluralismo y la democratización), hasta las más conservadoras (que asocian el capital social a un compromiso dogmático con estructuras familiares tradicionales y con un orden moral colectivo fundado en valores tradicionales). Esas posturas ideológicas están representadas en un continuo ideológico que va desde la confor- 
midad con las estructuras socioeconómicas nacionales existentes, hasta las visiones de una necesidad de transformación total de sistemas profundamente injustos e inequitativos.

A modo de síntesis, digamos que de acuerdo a lo anteriormente expuesto, existen dos enfoques principales encontrados tanto en los fundadores como en los continuadores del tema de capital social. El primero se centra en el conflicto, al destacar la existencia de desigualdades en las dotaciones de capital social y en el uso de éste para la conservación de posiciones de poder, considerando el conflicto político y el conflicto interno en las comunidades. El segundo enfoque destaca el consenso, la cooperación y la coordinación, aspectos más relacionados con la confianza y la posibilidad de entregar herramientas y capacidades a los menos dotados. Tanto, partidarios del neo institucionalismo, como las instituciones internacionales mencionadas y buena parte de la literatura sobre el tema, suelen destacar esta última perspectiva.

En relación con la pregunta de si el capital social puede ser considerado una teoría o un paradigma, existen diferentes puntos de vista. Por un lado, Filgueira (2003) plantea a este respecto que, "tal como lo conocemos en sus formulaciones actuales, no parece razonable esperar que el concepto de capital social pueda tener el status de una teoría aunque nadie puede anticipar el alcance que con el tiempo puede llegar a tener". Por otro lado, Robinson, Siles y Schmid (Atria 2003) consideran que,

a medida que los paradigmas maduran, la opinión propuesta sobre dicho asunto recibe la aceptación general de los expertos en el tema. Un paradigma maduro puede facilitar la acción cooperativa en un ámbito determinado, puesto que reduce los conflictos y gastos inherentes a la concertación de un acuerdo. El paradigma del capital social describe la influencia que ejercen las relaciones sobre las transacciones sociales, emocionales y económicas, y contiene conceptos extraídos de casi todas las ciencias sociales (Filgueira, 2003: 66).

Para estos autores, la importancia del paradigma del capital social no radica en que sus elementos individuales sean totalmente 
nuevos, sino en que, al reunir los diversos elementos del paradigma y examinar su interdependencia, se ha aprendido mucho más que cuando esos elementos se estudiaban en forma separada ${ }^{12}$.

A pesar de las críticas que se le han hecho al concepto de capital social, aquí se quiere defender la idea acerca del potencial teórico que este tiene para analizar el problema tanto del desarrollo como de los sistemas regionales de innovación. No se pretende asumir en el presente análisis del capital social una visión acrítica ni mesiánica ${ }^{13}$, pero sí reconocer la importancia que este concepto puede llegar a tener cuando se trata de abordar el problema del desarrollo en las sociedades actuales.

Para el autor del presente trabajo, el capital social es un tema, que ha tenido un tratamiento riguroso desde las ciencias sociales y humanas y como tal goza de una amplia aceptación tanto en comunidades científicas como académicas, que se han dedicado a su

12. En relación con la discusión acerca de si el capital social puede ser considerado un paradigma de las ciencias sociales, es necesario aclarar lo que se entiende aquí por la noción de paradigma. En el campo de la ciencia, Kuhn usa el término paradigma en dos sentidos diferentes. En sentido sociológico significa la constelación de creencias, valores, técnicas, etc., que comparten los miembros de una comunidad dada. En sentido filosófico denota una especie de elemento de tal constelación, las concretas soluciones de problemas que, empleadas como modelos o ejemplos, pueden remplazar reglas explícitas como base de solución de los restantes problemas de la ciencia, que él denomina, normal. En este caso se trataría de los paradigmas como ejemplares logros del pasado; por lo tanto, para este científico, un paradigma es lo que comparten los miembros de una comunidad científica y, a la inversa, una comunidad científica consiste en unas personas que comparten un paradigma. Puesto que una manera de comprender los conceptos es tratar de asemejarlos con otros, la descripción que de paradigma hace Ibarra, J., es la que mejor explica el concepto. Según este autor, un paradigma se asemeja a la normas de un juego: una de las funciones de las reglas es definir el campo de juego y el conjunto de posibilidades en ese campo.

${ }_{13}$ La visión acrítica y mesiánica frente al capital social, es una postura que suele criticarse en algunos círculos académicos, por considerarse que en ocasiones se le otorga al capital social demasiado atributos orientados para resolver problemas sociales que en la práctica no es posible lograr. A este respecto plantea Pedro E. Guell, la siguiente crítica: "Cuando se lee y oye la reseña de las virtudes del capital social se vienen a la mente las imágenes de los antiguos vendedores de las plazas de pueblo. Esos que ofrecían bálsamos milagrosos capaces de sanar todos los males, los del cuerpo y los del alma" (Guell, 2002: 7). 
estudio. Dicho concepto, ofrece valiosas posibilidades para el análisis de grupos, organizaciones, instituciones y sociedades menos desarrolladas, como es el caso de las sociedades latinoamericanas desde una perspectiva inter y transdisciplinar. No se pretende aquí reivindicar una concepción ingenua o simplista del capital social, por el contrario se es consciente del nivel de complejidad que reviste el tema, el cual constituye un campo de trabajo investigativo abierto a exploraciones futuras, tanto en su dimensión teleológica como aplicativa o instrumental ${ }^{14}$.

Concluyamos este apartado, afirmando que más que un término de moda o una fórmula mágica, el capital social es una apreciable posibilidad de construir o reconstruir aquellos vínculos humanos, requeridos para el desarrollo en general y para el desarrollo humano en particular, sobre todo en contextos sociales menos desarrollados.

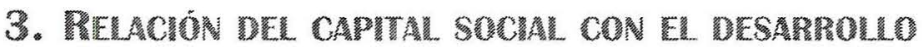

Ni la vida privada ni la coexistencia social son posibles sin mapas colectivos de sentido, sin una idea de lo que queremos hacer juntos.

Pedro E. Guell

En la actualidad, cualquier análisis o formulación de políticas públicas que se realice con respecto al desarrollo, no puede dejar de lado el tema del desarrollo humano, porque como afirma Boisier (2003) “Si el desarrollo no es humano, ¿qué entelequia sería?". El presente apartado estará dedicado al análisis de la relación entre el capital social y el problema del desarrollo. Se intentará construir un argumento mediante el cual se logre demostrar que en

14 Es importante no perder de vista que una cosa es el capital social como teleología de la sociedad contemporánea, es decir como una posibilidad interesante de llevar a cabo en un territorio o región concretos, y otra cosa es analizar como se da el capital social en las prácticas culturales reales, a modo de hechos sociales susceptibles de ser investigados. 
las sociedades actuales menos desarrolladas, no es posible lograr niveles de desarrollo, entendido desde la perspectiva del desarrollo alternativo que ya se ha mencionado, sin la existencia de aquellos valores fundamentales que conforman el llamado capital social.

Como ya se ha afirmado en líneas anteriores, la revisión de buena parte de la literatura existente acerca del concepto capital social, permite afirmar que existe un consenso en la mayoría de los autores dedicados al tema, acerca de la connotación que tiene este concepto, asociado al conjunto de normas y valores de interacción humana que tienen lugar, en una determinada región o territorio. Valga decir, que redunde en beneficio del desarrollo de las personas que habitan y construyen esa región o territorio.

El capital social concebido de esta manera tiene como propósito privilegiar el desarrollo colectivo ${ }^{15}$ sobre el desarrollo individual de las personas. Esta afirmación podría sonar como perogrullada, pero no lo es. Una mirada desprevenida e ingenua del capital social puede llevar a concluir que la existencia de capital social en una comunidad determinada, per se, es garante de desarrollo colectivo, pero resulta que no es así. Fukuyama (Atria 2003) advierte de la existencia en algunas sociedades de cierto capital social que sin duda alguna se constituye en obstáculo para el desarrollo colectivo, ya que tiene como propósito fundamental la persecución de intereses particulares en detrimento de los intereses generales o colectivos.

${ }_{15}$ Se puede identificar una división de criterios entre autores que consideran que el capital social es privativo de individuos y autores que piensan que es un atributo de colectividades o grupos. Según Coleman (1990), una característica fundamental del capital social consiste en el hecho de que a diferencia del capital privado, el capital social tiene la naturaleza de bien público. En este sentido es sugerente la propuesta de Durston (2003) de clasificar al capital social de acuerdo a sus usos y vínculos. Este autor sugiere cuatro tipos de capital social. El individual, que corresponde al crédito de reciprocidad u obligaciones que posee una persona por medio de sus relaciones; el de grupos pequeños cerrados; el comunitario, que se encuentra en las instituciones socioculturales que posee la comunidad; y el capital social externo a la comunidad, que se concreta en articulaciones verticales con el resto de la sociedad. 
Un ejemplo de lo anterior lo constituyen aquellas sociedades o comunidades que han instaurado como parte de su capital social comportamientos como el nepotismo, el amiguismo o el clientelismo. Estos comportamientos mencionados, son nefastos para el desarrollo colectivo porque minan valores como la confianza y la credibilidad y fortalecen valores como la corrupción. Por tanto, concluye Fukuyama y con él otros autores, este es un tipo de capital social que en sociedades que aspiren a fomentar procesos de desarrollo colectivo debe ser extirpado de raíz.

Por tanto, en el análisis que aquí se pretende hacer acerca de la relación capital social y desarrollo, el interés básico está enfocado en aquellos valores orientados a la construcción de capital social que fortalezca vínculos humanos, en los cuales se privilegie la búsqueda de un desarrollo colectivo. Algunos de esos valores constitutivos del capital social, entendido de esta manera son: la confianza, la reciprocidad, la cooperación, la solidaridad, el altruismo, el respeto, la tolerancia, la participación. Estos son valores que tienen sus raíces en la cultura ${ }^{16}$ y que son esenciales para el desarrollo.

Veamos algunos rasgos característicos de esos valores constitutivos del capital social, que acabamos de enunciar.

El valor de la confianza es valor que más ha llamado la atención entre los teóricos del capital social. La confianza puede definirse como una actitud basada en la expectativa del comportamiento de la otra persona que participa en una relación, y en el afecto que existe

16 Entre los teóricos más importantes del capital social existe el debate sobre si es la cultura o es la estructura social la que fundamenta al capital social. Es decir, el capital social se determina por los valores, normas y costumbres que se internalizan durante la infancia, o más bien nace de interacciones sociales que con el tiempo adquieren permanencia y generan reglas de juego como las normas, reglamentos, leyes, entre otras. Acerca de este problema consideramos que ambas aproximaciones (cultura y estructura) se complementan. Cultura se entiende aquí como aquellos valores, normas y bienes materiales característicos de un determinado grupo. Estructura se entiende como aquellas regularidades auto-yacentes que miden las relaciones sociales en las que las personas están inmersas. Los rasgos estructurales de la sociedad tienen una gran influencia en nuestro comportamiento como individuos y a su vez en nuestras acciones recreamos aquellas características estructurales. 
entre ambos. Esta implica la voluntad de aceptar riesgos, lo que supone que otras personas responderán como se espera, ofreciendo apoyo mutuo, o al menos sin intención de causar daño.

Según el antropólogo John Durston (Atria 2003),

la confianza tiene un soporte cultural en el principio de reciprocidad y su presencia o ausencia es producto, no de una programación rígida de una cultura 'ancestral', sino de la iteración de interacciones con otras personas, que demuestran en la experiencia acumulada que responderán a un acto de generosidad, alimentando un vínculo que combina la aceptación del riesgo con un sentimiento de afectividad o de identidad ampliada.

Desde el análisis sociopolítico, la confianza se relaciona estrechamente con la solidez de las organizaciones y su funcionamiento. A pesar de esta importancia, es poco lo que se ha trabajado respecto a dicho concepto, de cuáles son sus bases socioculturales y de sus variantes o mecanismos. A este respecto es importante reconocer los trabajos de autores como Misztal (Atria 2003), quien ha realizado un valioso análisis de la confianza en las sociedades modernas. Esta autora llama la atención acerca de que la confianza dejó de ser un asunto medular en el análisis social y económico en siglo XX, cuando las ciencias sociales abandonaron su preocupación moral acerca de los efectos desintegradores de la industrialización y la modernización. Una prueba de ese abandono es que los dos paradigmas sociológicos dominantes durante buena parte del siglo pasado (el funcionalismo estructural y el marxismo) prácticamente ignoraron el tema de la confianza, pues sus intereses estaban orientados hacia individuos y grupos sociales enfrascados en la búsqueda racional de sus intereses. Esta situación empieza a cambiar a partir del cuestionamiento de las instituciones sociales y su debilitamiento como factor de integración y cohesión social como producto de la crisis del Estado Benefactor, volviendo a ubicar a los individuos, sus identidades y comunidades en centro de atención.

Otro valor que se constituye en fuente de capital social de gran importancia, es la reciprocidad. En ciencias sociales, y par- 
ticularmente en antropología, el concepto de reciprocidad se ha construido con base al clásico trabajo titulado Ensayo Sobre el Don, de Marcel Mauss (1971). En dicho texto el autor identifica a la reciprocidad como principio regidor de las relaciones institucionales tanto formales como informales a nivel de comunidades. En sociedades premercantiles y mercantiles existe una lógica de intercambio ajena a la lógica del mercado, que involucra el intercambio basado en obsequios que pueden ser objetos, ayudas o favores. Esos obsequios pueden llegar a constituirse en un gesto de disposición a iniciar una relación social y una obligación culturalmente sancionada a retribuir. El individuo provee un servicio a otro o actúa para el beneficio de otros, pero en la expectativa de que esto le será devuelto en algún momento en caso de necesidad. En este sentido, el valor de la reciprocidad se constituye en la base misma de las relaciones e instituciones de capital social, pues en una comunidad donde la reciprocidad es fuerte, las personas se preocupan por los intereses de los otros, generándose de esta manera vínculos significativos.

Un tercer valor constitutivo de capital social es la cooperación, esta se puede definir como la acción complementaria orientada al logro de los objetivos compartidos de un emprendimiento común. La cooperación emerge asociada con la confianza y los vínculos de reciprocidad, como un resultado de la frecuente interacción individual.

Sumado a los anteriores valores, mencionemos como fuente primordial de capital social el valor de la solidaridad. En Hume (1740), encontramos una descripción acerca de la importancia de la solidaridad entre los seres humanos, dice Hume:

Las mentes de todos los hombres son similares en sus sentimientos y funcionamiento; ninguno de ellos puede reaccionar ante un afecto frente al que los demás no sean susceptibles en alguna medida. Al igual que las cuerdas de un instrumento que se tensan de la misma forma, el movimiento de uno se comunica a los demás; de una persona a otra, provocando movimientos similares en todas las criaturas humanas. 
La solidaridad en los términos utilizados por Hume adquiere rasgos de sentimiento de una persona o un grupo hacia otras personas o grupos. Esos sentimientos pueden incluir manifestaciones de admiración, interés, preocupación, empatía, consideración, respeto, sentido de obligación o confianza.

Fukuyama (Atria 2003) plantea una agenda de problemas relacionados con el capital social, que se constituyen en líneas de trabajo investigativo importante para sociedades menos desarrolladas, como es el caso de América Latina. Según el criterio de este autor (criterio que compartimos), existen en la actualidad necesidades de conocimiento sobre el tema del capital social al menos en cinco áreas, que son las siguientes: 1) necesidad de más información compartida sobre los casos en que el capital social ha sido creado con éxito, y donde no lo ha sido; 2) necesidad de conocer mejor las condiciones formales legales-institucionales para promover el capital social; 3) necesidad de examinar con mayor detalle la cuestión del capital social y la corrupción política; 4) necesidad de conocer mejor la relación entre capital social y cambio cultural; 5) intersección entre capital social, democracia y reforma económica.

Para Boisier (2003b) el problema del desarrollo en las actuales sociedades del conocimiento requiere ser analizado desde la perspectiva del aprendizaje colectivo. Según él, cualquier sociedad debe ser comprendida como un sistema complejo que tiene la capacidad de auto realizarse y para el logro de tal auto realización cumple una función muy importante la capacidad de aprendizaje colectivo. $\mathrm{El}$ aprendizaje colectivo requiere de fuertes dosis de capital social en términos de redes de cooperación permanentes o no, basadas en la confianza interpersonal, capaces de operar en contextos de "reciprocidad difusa"17.

A este respecto, plantea Kliksberg (1999), lo siguiente:

17 El término reciprocidad difusa hace alusión a aquellos niveles de incertidumbre que caracterizan a las interacciones sociales que tienen lugar en las sociedades contemporáneas. 
La cultura es el ámbito básico en que una sociedad genera valores y los transmite de generación en generación. En América Latina, promover y difundir sistemáticamente valores como la solidaridad (de profundas raíces en las culturas indígenas autóctonas), la cooperación, la responsabilidad de los unos por los otros, el cuidado conjunto del bienestar colectivo, la superación de las discriminaciones, la erradicación de la corrupción, la democratización y la búsqueda de una mayor equidad (en una región tan marcadamente desigual), claramente ayudará al desarrollo además de contribuir a conformar el perfil de la sociedad.

\section{NCUDENCIA DEL CAPITAL SOCIAL EN LOS SISTEMAS REGLONALES DE INNOVACIÓN}

Hasta aquí se ha realizado un recorrido conceptual por algunos términos considerados de interés para el análisis del problema planteado, entre ellos, los conceptos de capital social y sistemas regionales de innovación. El objetivo de este apartado es desarrollar algunas ideas acerca de la articulación que desde la perspectiva de análisis que se viene trabajando, se puede identificar entre capital social y sistemas regionales de innovación. A este respecto, algunas preguntas que pueden servir como derrotero para el análisis, son las siguientes: ¿Qué relaciones se pueden establecer entre capital social y sistemas regionales de innovación? ¿Cómo inciden los valores que conforman el capital social en la innovación, entendida como un proceso de construcción de conocimiento? ¿Son compatibles los valores requeridos para la conformación de sistemas regionales de innovación con los valores que conforman el capital social?

En líneas anteriores se realizó una caracterización de los sistemas regionales de innovación a partir de los aportes realizados por diferentes autores, pero aquí se considera que la caracterización que ofrece un mayor nivel de pertinencia, teniendo en cuenta la perspectiva del análisis que nos ocupa, es la propuesta por Edquist y Hommen. Vamos a analizar a continuación algunas de las características de los sistemas de innovación, propuestas por Edquist y 
Hommen (Arocena y Sutz, 2003), que revisten importancia para el análisis del presente apartado.

Según Edquist y Hommen el estudio de los sistemas de innovación, adopta una perspectiva holística e interdisciplinaria, pues procura abarcar el conjunto más amplio posible de determinantes de la innovación e incluye aspectos que se refieren no sólo a lo económico sino también a lo político y lo cultural. Esta es una característica que vincula el estudio de los sistemas de innovación con la perspectiva de análisis del capital social que se ha discutido en el presente trabajo. El interés por el estudio de los sistemas de innovación que involucra aspectos como el político y el cultural, es un interés también propio de los estudios relacionados con el capital social. Esto, teniendo en cuenta que el objeto de estudio del capital son las interacciones que ocurren entre actores sociales, organizaciones e instituciones, teniendo siempre presente que el acontecer de esas interacciones se producen en contextos política y culturalmente construidos.

Otra de las características que interesa analizar es aquella que considera acorde con los estudios sobre sistemas de innovación, utilizar perspectivas históricas para tomar en cuenta que los procesos de innovación conllevan retroalimentaciones entre diversos factores -en especial, conocimiento, innovación e instituciones-, cuyas evoluciones a lo largo del tiempo, por consiguiente, se influencian mutuamente. Según esta característica, para estudiar los sistemas de innovación es necesario observar las retroalimentaciones que se producen en la triada conocimiento-innovación-instituciones.

Recuérdese que el capital social tiene como preocupación, por un lado las interacciones sociales que se producen en la participación de los actores que intervienen al interior de las instituciones y por otro lado entre las diferentes instituciones que interactúan en una determinada región. De acuerdo con esta característica, la innovación es un proceso de construcción de conocimiento que debe ser analizado teniendo en cuenta las dinámicas que suceden en esa tríada indisoluble conformada por conocimiento-innovacióninstituciones. 
La perspectiva histórica de los procesos de innovación hace referencia a que los factores mencionados (conocimiento, innovación e instituciones) pueden ser analizados y comprendidos con mayores niveles de precisión en la medida que son abordados teniendo en cuenta su comportamiento evolutivo en el tiempo. En buena medida el conocimiento del estado actual de esos factores en un contexto determinado, está supeditado al análisis que se haga de su comportamiento pasado.

También encontramos como característica de los sistemas de innovación, que el estudio de estos no busca definir un sistema óptimo expresado en términos abstractos sino comparar sistemas existentes, en particular a través de sus diferencias. Es una idea aceptada por diferentes autores que el análisis de los sistemas de innovación privilegia un método de investigación de carácter comparativo, pero teniendo como referente de observación las diferencias existentes entre sistemas de innovación ${ }^{18}$. Para el establecimiento de esas diferencias es de gran utilidad tanto epistemológica como metodológica el énfasis que ponen los estudios sobre capital social, en las características culturales de interacción política y social por las cuales puede identificarse una comunidad localizada en un territorio o región específicos. Esas singularidades culturales que se constituyen en objeto de estudio del capital social, pueden coadyuvar al reconocimiento de las diferencias entre sistemas regionales de innovación.

La siguiente característica que interesa analizar, es aquella que enfatiza la interdependencia y las interacciones, ya que en los procesos de innovación y en sus actores influyen no sólo los elementos del sistema sino las relaciones entre estos. Aquí encontramos un vínculo estrecho entre la metodología que utilizan los

18 El análisis comparativo de los sistemas de innovación en este sentido no tiene pretensiones teleológicas, es decir no tiene como centro de interés la búsqueda de optimización de un sistema de innovación imaginario. Más bien le interesa abordar sistemas de innovación concretos, los cuales como se ha analizado obedecen a particularidades sociales, históricas y culturales y admiten ser comparados entre ellos. 
estudios de redes sociales, la cual tiene como enfoque fundamental la observación del tipo de relaciones que se dan entre actores o nodos, con la metodología utilizada en los estudios de capital social que tienen como propósito identificar aquellos valores que caracterizan las relaciones entre actores sociales que interactúan en una comunidad determinada. De ahí que sea muy importante observar las relaciones que se producen en las redes sociales que configuran los sistemas regionales de innovación y la incidencia que tiene el capital social en tales interacciones.

Además encontramos como característica de los sistemas de innovación, que estos atienden tanto a la tecnología como a las transformaciones organizativas, lo que ayuda a la comprensión de las complejas relaciones entre la innovación y otros procesos sociales. Esta característica contribuye a la comprensión acerca de que los sistemas de innovación tecnológica no pueden ser entendidos de manera aislada, pues estos tienen como condición necesaria las transformaciones organizativas que viabilizan esas innovaciones tecnológicas. La introducción o mejoramiento de capital social en procesos de innovación tecnológica o de cualquier otra índole, se constituye a su vez en innovaciones de carácter organizativo y viceversa. La relación entre sistemas de innovación y capital social que plantea esta característica es bien pertinente, si se tiene en cuenta la existencia frecuente de algunas concepciones acerca de que la innovación tecnológica poco o nada tiene que ver con las transformaciones sociales que estas requieren. Por el contrario, la innovación tecnológica y las transformaciones organizativas son dos caras de la misma moneda y la una incide en la otra de manera dialéctica.

Una última característica de los sistemas de innovación es aquella que destaca el papel central de las reglas, normas y leyes, como forma de entender las influencias sociales en el comportamiento innovativo. Es un hecho incuestionable que en la innovación entendida como sistema social, cumplen una función básica comportamientos que están sujetos a reglas, normas y leyes con las que están comprometidos los actores sociales, las instituciones y 
organizaciones que participan en la construcción de la innovación. El reconocimiento de la característica en mención, vincula de una manera contundente el análisis de los sistemas regionales de innovación con el tema del capital social, porque uno de los pilares constitutivos del capital social es la confianza que se construye entre los actores sujetos de interacción en una determinada región, soportada en el respeto a esas reglas, normas y leyes.

A modo de síntesis acerca de las ideas expuestas en este apartado, digamos que para la existencia y funcionamiento de los sistemas regionales de innovación, en los términos que han sido caracterizados aquí, se requiere de un conjunto de dinámicas no sólo económicas, sino también sociales y culturales que contribuyen a crear las interacciones entre todos los actores, organizaciones e instituciones que conforman el sistema. Entre más ricas sean esas dinámicas de interacción, mejor va a ser el funcionamiento de los sistemas regionales de innovación y a ello puede contribuir la construcción de los valores constitutivos de capital social que han sido analizados. Obviamente esto no es una tarea simple ni mecánica, por el contrario, como ya se ha dicho de manera recurrente, estos son procesos de alta complejidad que requieren ser abordados de manera sistémica teniendo en cuenta que son muchas las dimensiones y variables que allí se ponen en juego, las cuales es necesario aprender a conjugar. En eso radica su secreto.

\section{CUNCUSBONES}

En los últimos años han aparecido señales en diversas latitudes del planeta, indicadoras de que en los actuales momentos existe una demanda mundial por enriquecer la visión del desarrollo sobre todo en aquellos países que presentan menos niveles de superación de problemas como la pobreza. Prueba de ello es que los principales foros mundiales dedicados al problema del desarrollo hoy hablan de capital social, como una de las agendas prioritarias del tema del desarrollo.

Pese a las críticas que puede hacerse a la teoría del capital social, esta es una herramienta conceptual que si se sabe aprove- 
char, puede llegar a constituirse en valioso aporte para aquellas sociedades que cuentan con modelos de desarrollo incompletos. Son muchas las voces e iniciativas que en el mundo menos desarrollado, constatan la validez de ensayar nuevas estrategias sociales que ayuden a contrarrestar los efectos negativos del modelo de desarrollo economicista tradicional. Un ejemplo de ello, es la estrategia del Banco Interamericano de Desarrollo, de crear la Iniciativa Interamericana de Capital Social, Ética y Desarrollo ${ }^{19}$, la cual considera que el capital social es un tema eje de la agenda actual en América Latina.

América Latina es una paradoja andante, teniendo en cuenta que a pesar de su enorme riqueza económica representada en los recursos potenciales que posee, se constituye en una región en la que prevalecen ingentes niveles de pobreza, inequidad y desigualdad social y en este sentido aunque el capital social no es la nueva llave mágica para el desarrollo, sí puede ayudar a resolver esa enorme paradoja.

De acuerdo con lo anterior, la idea de capital social es un nuevo reto epistemológico y cognoscitivo para repensar el problema del desarrollo. Es más, se puede afirmar que el capital social abre una nueva agenda acerca del desarrollo, pues si el capital social funciona de manera adecuada, por esa vía es posible esperar que se favorezcan las otras formas de capital, que conforman a las sociedades.

La teoría del capital social se constituye en una valiosa herramienta para el análisis de los sistemas regionales de innovación, desde la perspectiva alternativa del desarrollo humano, sobre todo en el contexto de las sociedades contemporáneas, que como plantea Touraine (1997), se caracterizan por atravesar por una

19 Esta iniciativa en la actualidad está organizada en cuatro grandes áreas de acción: 1) colocar los temas de la ética y del capital social en el centro de la agenda colectiva para América Latina; 2) propugnar por que la ética y el capital social aparezcan en proyectos concretos de desarrollo; 3) impulsar una red de universidades de la región para la enseñanza de la ética; 4) apoyo a iniciativas de voluntariado provenientes de la sociedad civil. 
fase de desmodernización. Según este autor, la desmodernización es un rasgo marcado en las sociedades actuales del mundo, que se evidencia en comportamientos como la desocialización, la desinstitucionalización y la despolitización.

La desocialización es la desaparición de los roles, normas y valores sociales mediante los cuales se construía el mundo vivido. La desinstitucionalización se entiende como el debilitamiento o la desaparición de las normas codificadas y protegidas por mecanismos legales, es decir, la desaparición de los juicios de normalidad, que se aplicaban a las conductas regidas por instituciones. La despolitización es el producto de la crisis de representatividad y de confianza en los partidos políticos; el orden político ya no constituye el orden social.

La desmodernización planteada en estos términos, es una crisis de aquellos elementos sobre los cuales estuvo fundado el proyecto de la modernidad. Según el autor esta crisis es una mutación que trae efectos positivos, pues prepara un desplazamiento del análisis sociológico desde el sistema hacia el actor.

Frente al quiebre de aquellos valores que servían de soporte al proyecto sociopolítico de la modernidad, es necesario identificar alternativas que contribuyan a pensar en la construcción de interacciones sociales en contextos sociales que tienen carencias a este respecto, como es el caso de algunas sociedades menos desarrolladas. Por ello, se ha elegido el capital social como un concepto que puede llegar a ser útil para el estudio de los sistemas regionales de innovación.

En la actualmente denominada sociedad del conocimiento suele atribuirse el subdesarrollo de las sociedades, a causas relacionadas con la falta de crecimiento económico, como consecuencia de las debilidades en los procesos de innovación científica y tecnológica, desde una perspectiva lineal, como si existiera una ecuación infalible que dictamina que el desarrollo científico produce desarrollo tecnológico, y éstos a su vez, son causantes del desarrollo social. Diversos análisis han demostrado que la realidad no funciona de esta manera tan lineal y simplificada. 
Diferentes estudios realizados por autores dedicados al tema del desarrollo durante los últimos años, muestran que este es un problema cuya explicación no se puede reducir a las dimensiones económica, científica y tecnológica, las cuales si bien es cierto que son importantes, no son suficientes para comprender su complejidad. Es así como, en los análisis sobre el desarrollo empieza a reconocerse y a dársele una valoración relevante a dimensiones como la cultura y la política y a capitales denominados intangibles como el capital social.

Ese reconocimiento del carácter pluridimensional que tiene el desarrollo, hace necesario que el estudio de componentes tan importantes como la innovación, amerite ser abordada desde una perspectiva sistémica, dando así lugar a lo que se ha denominado sistemas de innovación.

Como se ha analizado anteriormente, los sistemas de innovación regional son construcciones sociales, en las cuales cumple una función primordial aquel conjunto de valores que conforman el capital social. No se pretende aquí defender la idea de que el capital social que posea una determinada sociedad, se constituye en la panacea infalible para resolver los problemas del subdesarrollo; pues esa sería una postura determinista y simplificadora de una problemática que, como ya se ha mencionado, reviste características de gran complejidad. Más que plantear que el capital social es condición necesaria y suficiente para el desarrollo en el contexto de los sistemas regionales de innovación, lo que se ha querido es llamar la atención acerca del potencial que tienen esos valores constitutivos de capital social, en tanto que formas importantes de construir vínculos y redes societales que coadyuven al fortalecimiento de los sistemas regionales de innovación desde perspectivas de desarrollos sociales alternativos que tengan como preocupación central el desarrollo humano. 


\section{BuLLogaria}

AROCENA, R. Subdesarrollo e innovación. Navegando contra el viento. Madrid: Ruiz de Alarcón, 2003.

ATRIA, R. Hacia un nuevo paradigma: Capital social y reducción de la pobreza en América Latina y el Caribe. Santiago de Chile: Naciones Unidas, 2003.

BAGNASCO, A. El capital social. Instrucciones de uso. Argentina: Fondo de Cultura Económica, 2003.

BERMAN, M. Todo lo sólido se desvanece en el aire. La experiencia de la modernidad. España: Siglo XXI, 2001.

BOISIER, S. 'El largo brazo de Descartes: usos y abusos del concepto de capital social en las propuestas de desarrollo'. En: la red: http://www.eclac. cl/publicaciones/, 2003.

‘Y si el desarrollo fuese una emergencia sistémica?'. En la red: http://www.clad.org.ve/rev27/boisier.pdf., 2003 b.

BOURDIEU, P. The Forms of Capital, en Richardson, J. G., Handbook of Theory and Research for Sociology of Education. New York: Greenwood Press, 1986.

BRONCANO, F. Mundos Artificiales. Filosofia del cambio tecnológico. México: Paidós, 2000.

COLEMAN, J. Foundations of Social Theory, Cambridge: Harvard University Press, 1990.

FILGUEIRA, C. 'Capital social: potencialidades analíticas y metodológicas para la superación de la pobreza'. En la red: http://www.eclac.cl/publicaciones/, 2003.

GIDDENS, A. Sociología. Madrid: Alianza Editorial, 1991.

GUELL, P. '¿Quién le apuesta al capital social en América Latina?'. En la red: http://www.desarrollohumano.cl/pdf/, 2002.

HUME, D. A Treatise of Human Nature, Oxford: Oxford University Press, 1740.

KLIKSBERG, B. 'Capital social y cultura, claves esenciales del desarrollo', Revista CEPAL 69: 85-102, 1999.

MAUSS, M. Ensayo sobre los dones. Motivos y forma del cambio en las sociedades primitivas, en Sociología y antropología. Madrid: Tecnos, 1971. 
PORRAS, J. Redes. Santiago de Chile: Universidad Bolivariana, 2005.

PORTES, A. 'La Sociología en el continente: convergencias pretéritas y una nueva agenda de alcance intermedio'. En la red: http://www.ejournal. unam.mx/rms/2004-3/RMS, 2004.

PUTNAM, Robert D. "Bowling Alone: America's Declining Social Capital". Journal of Democracy, 6, (1): 65-78. 1995.

TOURAINE, A. ¿Podremos vivir juntos? La discusión pendiente: el destino del hombre en la aldea global, Bogotá: Fondo de Cultura Económica, 1997.

VIGNOLO, C. 'Sociotecnología: construcción de capital social para el tercer milenio'. En la red: http://www.dii.uchile.cl, 2002.

WEBER, M. Economía y sociedad. Esbozo de sociología comprensiva. México: Fondo de Cultura Económica, 2002. 